\title{
NOVEL SCIENCE OR ORAL HISTORY? THE AdMissibility OF CO-PRODUCED INFORMATION IN CANADIAN COURTS
}

\author{
DAVID ISAAC ${ }^{*}$
}

\begin{abstract}
Co-production is an emerging source of information about the world, but it is one that has not been adequately theorized in the legal literature. Because co-production contains aspects of both novel science and oral history, it is not clear how it can be admitted. I argue that coproduced information does not clearly fit into either of the admissibility frameworks. With respect to the novel science framework, co-produced information fits into the criteria of testability, peer review, and standards with only a few problems, but would likely fail the general acceptance criterion of the test. However, if scientists are educated about coproduction, or if it is possible to delineate a group of scientists who are more likely to accept co-production as the "relevant group," then it may be possible for co-production to be admitted as evidence through the novel science framework. Turning to the oral history framework, co-produced information is less likely to be admitted because oral history is only a part, and not a necessary part, of co-produced information. As such, courts will likely be reluctant to bend the rules of evidence to admit it. Further research is needed to determine whether co-produced information can be admitted under the novel science framework.
\end{abstract}

TABle OF CONTENTS

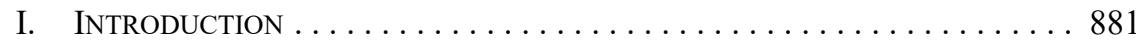

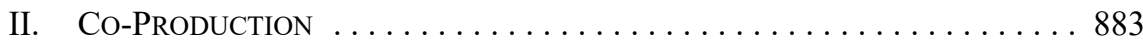

III. ADMISSIBILITY OF EVIDENCE IN CANADA $\ldots \ldots \ldots \ldots \ldots \ldots \ldots \ldots 86$

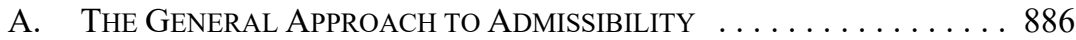

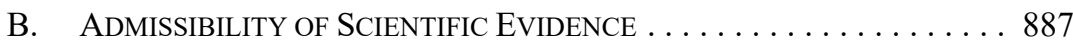

C. Admissibility of Novel SCIENTIFIC EvidenCE . . . . . . . . . . 889

D. AdMISSIBILITY OF ORAL HiSTORY EVIDENCE $\ldots \ldots \ldots \ldots \ldots . \ldots 890$

IV. AdMissibILITY of Co-ProducED KNOWLEDGE $\ldots \ldots \ldots \ldots \ldots \ldots 89$

A. Co-Production and Novel Scientific Evidence . . . . . . . 895

B. Co-Production and Oral History EvidenCE $\ldots \ldots \ldots \ldots . \ldots 90$

C. NeXt Steps . . . . . . . . . . . . . . . . . . . . 901

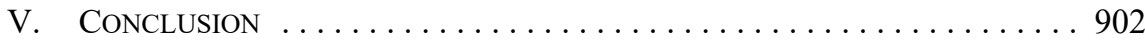

\section{INTRODUCTION}

In the last 20 years, there has been a growing trend of scientists working alongside Indigenous peoples to understand the world. This process is known as co-production. In these projects, Indigenous knowledge-holders work together with non-Indigenous scientists to jointly create information. When done well, both parties work together in a trusting relationship, each group bringing something useful to the table. The output of this process is a strengthened relationship between Indigenous and non-Indigenous peoples and a more

MA, JD, Student-at-Law, Lerners LLP, London, Ontario. Many thanks to Heather Douglas and Michael Coyle for their assistance. Thanks also to the anonymous reviewers who provided thoughtful feedback on this article, and to the participants at the 34th Annual Social Philosophy Conference at Loyola University, 15 July 2017 and the Commission on Legal Pluralism conference held at the University of Ottawa, 22-24 August 2018. Finally, thanks to my partner Rachel for her support. All remaining errors are mine alone. 
thorough understanding of the world. This process of co-production has become increasingly popular in the last decade and is a promising method of meaningful consultation, but it is not without its problems. Among these is the problem of how to admit co-produced information as evidence. While the methods of admitting novel scientific evidence and oral history evidence are well understood, co-produced evidence does not fit neatly into either category. Aspects of traditional knowledge may not meet the criteria for admissibility of novel scientific evidence. For instance, despite the recent popularity of co-production, it is still heavily criticized by some scientists and may not meet the "general acceptance" criterion. Likewise, because of the spiritual aspect of some Indigenous knowledge, it is not clear how testable co-produced information is. Furthermore, co-produced information does not fit into the admissibility framework for oral history evidence. This is because co-produced information is not oral history evidence, but rather can use oral history evidence. From this, we can see that the admissibility of co-produced information is under-theorized, and more scholarly work needs to be done in order to better understand how this useful method of understanding the world can be incorporated into the Canadian legal system.

A brief note on terminology: in this article I use the terms "Indigenous Peoples' Understandings" as opposed to "Traditional Knowledge," "Traditional Ecological Knowledge," or "Traditional Environmental Knowledge." There are several reasons for this. First, there is no consensus on what is meant by "Traditional Knowledge" and its variants. A survey of the literature indicates there are over a dozen different definitions of those terms. ${ }^{1}$ Second, and perhaps more importantly, the term "traditional" is problematic. It indicates a false homogeneity across Indigenous cultures, and constrains the knowledge to the past. ${ }^{2}$ Furthermore, "knowledge" is not necessarily an accurate word to describe the interactive process that the term "traditional knowledge" attempts to describe. ${ }^{3}$ As such, I will use the term "Indigenous Peoples' Understandings" (IPUs) as it avoids false

1 Martha Johnson, ed, Lore: Capturing Traditional Environmental Knowledge (Hay River: Dene Cultural Institute and International Development Research Centre, 1992); Winona LaDuke, "Traditional Ecological Knowledge and Environmental Futures" (1994) 5 Colo J Intl Envtl L \& Pol'y 127; Arun Agrawal, "Dismantling the Divide Between Indigenous and Scientific Knowledge" (1995) 26:3 Development \& Change 413; Rita A Miraglia, Traditional Ecological Knowledge Handbook: A Training Manual and Reference Guide for Designing, Conducting, and Participating in Research Projects Using Traditional Ecological Knowledge (Anchorage: Alaska Department of Fish and Game, 1998); Peter J Usher, "Traditional Ecological Knowledge in Environmental Assessment and Management" (2000) 53:2 ARCTIC 183; Henry P Huntington, "Using Traditional Ecological Knowledge in Science: Methods and Applications" (2000) 10:5 Ecological Applications 1270; Gloria Snively \& John Corsiglia, "Discovering Indigenous Science: Implications for Science Education” (2000) 85:1 Science Education 6; Robin Wall Kimmerer, "Weaving Traditional Ecological Knowledge Into Biological Education: A Call To Action" (2002) 52:5 Bioscience 432; Daniel J Gervais, "Spiritual But Not Intellectual? The Protection of Sacred Intangible Traditional Knowledge" (2003) 11 Cardozo J Intl \& Comp L 467; Fikret Berkes, Mina Kislalioglu Berkes \& Helen Fast, "Collaborative Integrated Management in Canada's North: The Role of Local and Traditional Knowledge and Community-Based Monitoring" (2007) 35 Coastal Management 143; Janna M Shackeroff \& Lisa M Campbell, "Traditional Ecological Knowledge in Conservation Research: Problems and Prospects for Their Constructive Engagement" (2007) 5:3 Conservation \& Society 343; Shravan Kalluri, "Traditional Knowledge and Patent Strategy" (2012) 17 J Intellectual Property Rights 430; Christina N Service et al, "Indigenous Knowledge and Science Unite to Reveal Spatial and Temporal Dimensions of Distributional Shift in Wildlife of Conservation Concern" (2014) 9:7 PLOS ONE 1.

Deborah McGregor, "Linking Traditional Ecological Knowledge and Western Science: Aboriginal Perspectives From the 2000 State of the Lakes Ecosystem Conference" (2008) 28:1 Can J Native Studies 139.

Glen S Aikenhead \& Masakata Ogawa, "Indigenous Knowledge and Science Revisited" (2007) 2 Cultural Studies of Science Education 539 at 553. 
homogeneity, does not root the term in the past, and better matches the participatory nature of this method of understanding the world. ${ }^{4}$ I define IPUs as follows:

[B]od[ies] of knowledge participated in by groups of people in particular Indigenous cultures. Any one member of those groups does not hold [them], rather, [they are] found in the culture of the groups. [They are] formed through engaging with the land over generations, and [are] often passed on orally. "Land" is defined broadly, so as to include language, people, animals, plants, water, and the earth, making [them] holistic in a very robust sense. The connection between these entities is often spiritual in nature. Because [IPUs have] been successfully used for so long, [they have] significant epistemic authority. Notwithstanding [their] long history, [IPUs are] fluid, and can change to incorporate new ideas and technologies. ${ }^{5}$

I pair the term IPUs with the term "Scientific Understandings" (SUs) as opposed to the terms "Western science," "wildlife science," "modern science," or "Western knowledge," which are typically used in the co-production literature. ${ }^{6}$ I avoid these terms because science is not a practice that is used exclusively in the Western world. ${ }^{7}$ Moreover, using an equivalent term — "understandings" - for both IPUs and SUs reflects the plurality of ways of knowing within and between the two ways of examining the world. By using complementary terms, I hope to put both ways of knowing on equal linguistic footing from the start. That being said, I acknowledge that the terms are doubtless problematic in some respect.

The first two parts of this article are primarily exegetical. Part II describes what coproduction is and how it can properly be performed. Part III outlines the general concept of admissibility of evidence in Canada before turning to the criteria for admitting novel scientific evidence and oral history evidence in greater detail. The admissibility of both novel scientific evidence and oral history evidence primarily comes down to whether it can be shown that the tendered evidence is reliable. Finally, in Part IV I turn to the argument about admissibility of co-produced information. After demonstrating that co-produced information ${ }^{8}$ does not fit neatly into either admissibility framework, I briefly consider a possible way forward.

\section{Co-Production}

In this section I examine what co-production is and how it relates to oral history evidence and expert scientific testimony. Broadly speaking, co-production occurs when scientists and Indigenous people work together to understand the world.

David Isaac, Values and Co-Production: Examining the Interface of Indigenous Peoples' Understandings and Scientific Understandings (MA Thesis, University of Waterloo Department of Philosophy, 2015) [unpublished].

5 Ibid at 21. Note that this definition is broader than that of oral history. While IPUs often incorporate oral history, they are not co-extensive with it, as they involve the lived experience of the person holding an IPU with the land.

$6 \quad$ Service et al, supra note 1; Snively \& Corsiglia, supra note 1; Johnson, supra note 1; Agrawal, supra note 1 .

7 See e.g. Helaine Selin, "Introduction" in Helaine Selin, ed, Encyclopaedia of the History of Science, Technology, and Medicine in Non-Western Cultures, 1st ed (Dordrecht: Springer Science+Business Media, 1997) xv at xv.

8 I use the term "information" throughout this essay to encompass both IPUs and SUs. 
Co-production of knowledge between [Indigenous people] and [scientists] is the creation of new information by working together to understand the world. It involves mutual understanding, interaction, and respect, as well as the recognition that each party brings something important to the discussion. ${ }^{9}$

This definition requires some unpacking. As it stands today, the process of co-production is unbalanced, with Indigenous peoples' understandings used to supplement scientific understandings. For instance, Deborah McGregor writes that " $[t]$ he field to date has focused more on gathering and documenting, using social science methods, those aspects of the knowledge base that are considered of value to external non-Native interests." 10 Scientists develop hypotheses about the world and use IPUs to test them. But where there is balance between the input from both groups, each is able to make contributions and criticisms of the other.

However, insofar as traditional knowledge develops theories of how the world is, science can be used as pieces of knowledge to support or refute certain ideas traditional knowledge puts forward. That is, science can be a tool in the hands of Indigenous people. ${ }^{11}$

The concept of co-production is built on the fact that the different participants have different experiences to examine the world through different lines of evidence. ${ }^{12}$ Successful co-production projects involve both groups contributing to the inquiry methods of the other. A good example of this can be found in a research project in Alaska that ran from 2002-2006 where scientists and Alutiiq residents worked side by side on the "[d]esign of the research questions, selection of the survey sites, and the actual fieldwork."13 The use of traditional knowledge alongside science helped the project gain a "more complete picture of the history and social-ecological context of recent field results."14

The fact that co-production is done by people with different perspectives on the world is important from both a social point of view, and for the purposes of ensuring that the information generated is accurate. From a social perspective, incorporating different perspectives helps build trust in the information generated. This is of particular importance for work done with Indigenous peoples, as there is a history of scientists treating Indigenous people as subjects of experiments, rather than as partners in research. ${ }^{15}$ In Canada's residential schools, Indigenous children were used as human subjects for researching malnutrition. Children were given insufficient amounts of certain nutrients for two years to generate a baseline, and then the amount of one nutrient was increased so scientists could determine what the effect of that nutrient was. ${ }^{16}$ In a similar study of nutritional supplements, "Indian Affairs officials went so far as to experiment with preventing some families from

Isaac, supra note 4 at 45 .

McGregor, supra note 2 at 146. See generally Isaac, ibid at 38-39.

Isaac, ibid at 39.

Service et al, supra note 1 at $7-8$.

Henry P Huntington et al, "Integrating Traditional and Scientific Knowledge Through Collaborative Natural Science Field Research: Identifying Elements for Success" (2011) 64:4 ARCTIC 437 at 439. Ibid.

Robyn L Sterling, "Genetic Research Among the Havasupai: A Cautionary Tale” (2011) 13:2 Virtual Mentor 113; Isaac, supra note 4 at 7.

Ian Mosby, "Administering Colonial Science: Nutrition Research and Human Biomedical Experimentation in Aboriginal Communities and Residential Schools, 1942-1952" (2013) 46:91 Social History 145. 
using Family Allowances to purchase flour — despite the fact that it had long been a key dietary staple." ${ }^{17}$ The history of experimentation on Indigenous peoples has followed a pattern: "they benefit little from the technologies, businesses, and conservation projects of members of dominant societies like the US, yet they suffer harms from the direct consequences." 18

By working alongside Indigenous peoples, non-Indigenous people can fight this history of colonial science. When both parties participate in and benefit from the research they do together and when relationships are built such that Indigenous peoples can trust that their non-Indigenous partners will not use the information in a way that will harm them, ${ }^{19}$ coproduction can help promote effective management of natural resources. ${ }^{20}$ Note that coproduced information can be helpful as evidence outside the Aboriginal law context. For example, such evidence could be used in environmental law (such as determining the impact of a chemical spill), municipal law (such as determining the impact of wind turbines), or administrative law (in any board or tribunal touching on environmental matters).

The problem of accurate information is an important one, as we will discuss below. The reliability of information generated by a method of inquiry is critical for that information to be admitted by courts. ${ }^{21}$ As such, the fact that co-produced information is generated by people from a variety of backgrounds is important. ${ }^{22}$ Pluralistic approaches to inquiry, which are useful to eliminate bias, occur when people from more than one background work to understand a problem. Helen Longino in her book Science as Social Knowledge, argues that background assumptions that shape theories and hypotheses tend to remain hidden unless people with different points of view expose them. ${ }^{23}$ Where background assumptions are examined, inquiry improves because the "differing assumptions allow people to see how their assumptions influence their inquiry. As such, different background assumptions leads to a better understanding of the world." ${ }^{24}$ Because co-production projects have a built-in pluralist effect through synthesizing different ways of knowing, such projects can generate more accurate information. In this way, co-production projects may have an additional layer of reliability built into their methodology.

An example of co-production done well can be found in a 1999 paper by Nikolai Mymrin, The Communities of Novoe Chaplino, Sireniki, Uelen and Yanrakinnot, and Huntington.

Ibid at 157; Isaac, supra note 4 at 7.

Kyle Powys Whyte, "Now This! Indigenous Sovereignty, Political Obliviousness and Governance Models for SRM Research" (2012) 15:2 Ethics, Policy \& Environment 172 at 173.

This can involve some sacrifice on the part of the non-Indigenous researcher: see e.g. Shackeroff \& Campbell, supra note 1.

Cf Per Olsson, Carl Folke \& Fikret Berkes, “Adaptive Comanagement for Building Resilience in SocialEcological Systems" (2004) 34:1 Environmental Management 75 at 83 (while there are some differences between co-management and co-production, the role trust plays in both is very similar).

See Myers $v$ Director of Public Prosecutions, [1964] 2 All ER 881; $R$ v Smith, [1992] 2 SCR 915 [Smith]; $R$ v Khelawon, 2006 SCC 57.

Cf Paul Feyerabend, Science in a Free Society (London: New Left Books, 1978) at 106; Helen E Longino, Science as Social Knowledge: Values and Objectivity in Scientific Inquiry (Princeton: Princeton University Press, 1990) at 76; Carla Fehr, "What Is in it for Me? The Benefits of Diversity in Scientific Communities" in Heidi E Grasswick, ed, Feminist Epistemology and Philosophy of Science: Power in Knowledge (New York: Springer, 2011) 133.

Longino, ibid.

Isaac, supra note 4 at 44 . 
This project was researching beluga whales in Russia, and involved the Indigenous peoples of the area throughout the research process.

\begin{abstract}
The participants in the project were selected with the help of the community council and elders in each village. Mymrin began the research with group or individual interviews, recording them on tape. Later, he prepared printed reports and returned these to the participants for corrections and additions. Following this review, he again conducted individual interviews, asking questions to clarify and expand what was in the report. During this stage, some of the hunters wrote to him and submitted additional notes. This information has been added to the relevant sections of the report. Huntington and Mymrin (1996) include the text of these contributions along with descriptions of the participants and their experiences. ${ }^{25}$
\end{abstract}

This example demonstrates good relationship building, and the opportunity for feedback by the communities at every stage of the process. Moreover, the communities are listed as authors of the paper, helping work against the erasure of Indigenous groups from research.

\title{
III. Admissibility of EvidenCe in CANADA
}

I will begin this section by examining the general approach to admissibility of evidence in Canada, giving a brief overview of the fundamental rule of evidence, relevance, the hearsay rule, and the principled exception to that rule. Next, I will explain the leading case on admissibility of novel scientific evidence, and conclude the section with a discussion on admissibility of oral history evidence.

\section{A. The General Approach to Admissibility}

Courts make decisions based on evidence. Generally speaking, courts want to admit as much evidence as possible, as this leads to better informed decisions. The fundamental rule of evidence law is that "[e]verything that is relevant to a fact in issue is admissible" so long as there is no "legal reason for excluding it." ${ }^{26}$ The Supreme Court states this fundamental rule as follows:

Once evidence is found to be relevant, it is generally admissible and the jury is left to decide how much weight to give a particular item of evidence. Similarly, once evidence is determined to be relevant with respect to a particular live issue, the jury should normally be free to weigh the evidence in drawing conclusions about that live issue. This is subject to specific exclusionary rules and the judge's discretion to exclude evidence that is more prejudicial than probative. ${ }^{27}$

Relevance is based on two criteria. First, it is determined based on the question, "does the evidence offered render the desired inference more probable than it would be without the evidence?"28 This is determined on a matter of logic and experience. The second criterion is whether or not the evidence is probative of material facts. That is, whether the evidence

Nikolai I Mymrin et al, "Traditional Knowledge of the Ecology of Beluga Whales (Delphinapterus Leucas) in the Northern Bering Sea, Chukotka, Russia" (1999) 52:1 ARCTIC 62 at 63.

26 Hamish Stewart et al, eds, Evidence: A Canadian Casebook, 4th ed (Toronto: Emond Montgomery Publications, 2016) at 5.

$27 \quad R v$ White, 2011 SCC 13 at para 54.

28 Charles T McCormick, Handbook of the Law of Evidence (St Paul, Minn: West Publishing, 1954) at 318 , cited in Stewart et al, supra note 26 at 5 [emphasis in original]. 
gives information about a fact that is legally relevant given the nature of the case. So in general, all relevant evidence is admitted unless there is some exclusionary rule preventing its admission, and evidence is relevant when it tends to prove a material fact.

The largest problem for admissibility of oral history evidence was, historically, the hearsay problem. Hearsay is an out-of-court statement adduced for the truth of its contents, and is presumptively inadmissible. ${ }^{29}$ Because oral history evidence consists of statements made out of court, passed down through time, and then repeated in court, oral history evidence is hearsay. Traditionally, there have been many "pigeonhole" exceptions to hearsay. If a lawyer can prove that the out-of-court statement was, for example, made spontaneously, it could be admitted because there was little possibility of concoction or distortion by the declarant. ${ }^{30}$ More recently, courts have taken a broader approach to hearsay in what has become known as the principled approach. In this approach, hearsay evidence is admissible if it is both necessary and reliable, regardless of whether it fits into one of the traditional hearsay exceptions. ${ }^{31}$ The necessity criterion can be met if the original person who made the statement (the declarant) is unavailable. ${ }^{32}$ The reliability criterion can be met if the statement is made in circumstances such that the possibility of lies or mistakes is substantially reduced. As we will see, oral history evidence is capable of meeting these criteria.

\section{B. Admissibility OF Scientific Evidence}

The leading case on admissibility of expert scientific evidence in Canada is R. v. Mohan. ${ }^{33}$ Mohan sets out a four-part test for admissibility of expert evidence that requires the judge to examine relevance, necessity in assisting the trier of fact, the existence of an exclusionary rule, and whether the expert is properly qualified. ${ }^{34}$ The relevance criterion is the same as set out above in Part III.A. However, this criterion is given special weight in the context of expert evidence due to concerns about jury overvaluation. The worry is that expert evidence will be given too much weight, and will "distort the fact-finding process." ${ }^{35}$ When evidence is "[d]ressed up in scientific language which the jury does not easily understand and submitted through a witness of impressive antecedents, this evidence is apt to be accepted by the jury as being virtually infallible and as having more weight than it deserves." ${ }^{26}$ These concerns tend to arise most often in novel areas of science. ${ }^{37}$ As such, there are two factors that judges should consider to combat this:

(1) Is the evidence likely to assist the jury in its fact-finding mission, or is it likely to confuse and confound the jury?

Stewart et al, ibid at 129; Bond v Martinos, [1970] 2 OR 319 (CA).

$R v$ Clark (1983), 42 OR (2d) 609 (CA).

Stewart et al, supra note 26 at 195; $R$ v Khan, [1990] 2 SCR 531 [Khan]; Smith, supra note 21.

$R \vee B(K G)$, [1993] 1 SCR $740[B(K G)]$.

[1994] 2 SCR 9 [Mohan].

Ibid at 20.

Ibid at 21 .

Ibid.

See e.g. Alex J Smethurst, Christopher J Wilson \& Kimberly Collins, "The Influence of FMRI Lie Detection Evidence on Juror Decision Making Following Post-Trial Deliberations"(2015) 11:3 Applied Psychology in Criminal Justice 147 at 148. 
(2) Is the jury likely to be overwhelmed by the "mystic infallibility" of the evidence, or will the jury be able to keep an open mind and objectively assess the worth of the evidence? ${ }^{38}$

So in making a determination of relevance, a court must pay special attention to whether the credentials of the expert and the nature of the topic will have a prejudicial effect on the jurors such that the probative value of the evidence is overwhelmed.

With regard to necessity, the Supreme Court turns to R. v. Abbey, quoting the decision with approval in saying that "[w]ith respect to matters calling for special knowledge, an expert in the field may draw inferences and state his opinion. An expert's function is precisely this: to provide the judge and jury with a ready-made inference which the judge and jury, due to the technical nature of the facts, are unable to formulate." 39

As with relevance, the potential to distort the fact-finding process comes into play. If matters are simple enough that an expert is not needed, using one will only serve to confuse the jury. ${ }^{40}$ Similarly, there is a concern that the expert will "usurp the functions of the trier of fact." ${ }^{, 1}$ Judges (or juries) must decide what the facts of the case are, and whether allowing certain expert evidence in "could result in a trial's becoming nothing more than a contest of experts with the trier of fact acting as referee in deciding which expert to accept." 42

The third criterion is the absence of any exclusionary rule. ${ }^{43}$ The hearsay rule is an example of such a rule. As we will see, oral history evidence was traditionally considered hearsay, but judicial attitudes towards such evidence have changed in recent years.

The fourth criterion is that the expert must be properly qualified. ${ }^{44}$ Experts must have special knowledge through either study of or experience with the matters on which the expert is called to testify. ${ }^{45}$ Importantly, the expert does not have to have academic experience to be considered an expert. ${ }^{46}$

These criteria were modified slightly in a recent Ontario Court of Appeal case, $R$. $v$. Abbey. ${ }^{47}$ The test was broken into two parts to reflect the importance of the "gatekeeping" role of the court. ${ }^{48}$ The test is now as follows:

First, the party proffering the evidence must demonstrate the existence of certain preconditions to the admissibility of expert evidence. For example, that party must show that the proposed witness is qualified to give the relevant opinion. Second, the trial judge must decide whether expert evidence that meets the preconditions to admissibility is sufficiently beneficial to the trial process to warrant its admission despite

Mohan, supra note 33 at 22.

Ibid at 23, citing $R \vee$ Abbey, [1982] 2 SCR 24 at 42.

Mohan, ibid at 24.

Ibid.

Ibid.

Ibid at 25

Ibid.

Ibid.

$R v$ Marquard, [1993] 4 SCR 223 at 243 [Marquard].

2009 ONCA 624 [Abbey CA]. Note that this case is different than the case mentioned in note 39, above. Ibid at para 78. The "gatekeeper" role refers to the court's job of keeping junk science out of evidence. See e.g. The Honourable Justice Ian Binnie, "Science in the Courtroom: The Mouse That Roared" (2007) 56 UNBLJ 307. 
the potential harm to the trial process that may flow from the admission of the expert evidence. This "gatekeeper" component of the admissibility inquiry lies at the heart of the present evidentiary regime governing the admissibility of expert opinion evidence. ${ }^{49}$

This demonstrates the tendency of the courts to focus on the potential harm that experts can do. Because experts have such potential to sway juries, courts are extremely wary of allowing poorly done science as evidence.

\section{Admissibility OF Novel Scientific EvidenCe}

Because of the concerns courts have with expert testimony, novel science is given even more scrutiny than "regular" science. It is likely that co-produced evidence would be more likely to fit into the "novel science" category rather than the general "science" category, simply because the techniques and practice of co-production are relatively new. In R. v. J.L.J., the Supreme Court notes that older, well-established scientific techniques can be considered novel if they are used "for a novel purpose." ${ }^{50}$ While it is not clear that coproduction fits into either "science" or "novel science" at all, given the definition of coproduction above it is more likely that a court would consider co-produced information to be a novel use of an established scientific technique rather than a regular scientific practice. As such, we now turn to an examination of the test for admitting novel scientific evidence.

The Mohan test was modified in $J-L J$ to deal with the "special scrutiny" that must be given to novel science. ${ }^{51}$ The special scrutiny that novel science must undergo is due to the fact that there are reliability concerns with new scientific techniques arising from the fact that novel science is by definition relatively untested. As such, novel science must pass a "basic threshold of reliability" before it is admissible. ${ }^{52} J-L J$ sets out a new set of factors borrowed from the American case Daubert v. Merrell Dow Pharmaceuticals, Inc. ${ }^{53}$ for

evaluating the soundness of novel science ...

(1) whether the theory or technique can be and has been tested:

Scientific methodology today is based on generating hypotheses and testing them to see if they can be falsified; indeed, this methodology is what distinguishes science from other fields of human inquiry.

(2) whether the theory or technique has been subjected to peer review and publication:

[S] ubmission to the scrutiny of the scientific community is a component of "good science," in part because it increases the likelihood that substantive flaws in methodology will be detected.

(3) the known or potential rate of error or the existence of standards; and,

Abbey CA, ibid at para 76 .

2000 SCC 51 at para $35[J-L J]$.

Mohan, supra note 33 at $25 ; J-L J$, ibid.

Mohan, ibid.

509 US 579 (1993). 
(4) whether the theory or technique used has been generally accepted:

A "reliability assessment does not require, although it does permit, explicit identification of a relevant scientific community and an express determination of a particular degree of acceptance within that community."

Widespread acceptance can be an important factor in ruling particular evidence admissible, and "a known technique which has been able to attract only minimal support within the community," ... may properly be viewed with skepticism. ${ }^{54}$

These factors are designed to help determine whether a particular novel scientific technique is reliable enough for use as evidence. While they are problematic in some respects, they are only needed to determine threshold reliability. That is, they are used to determine if evidence is reliable enough to be admissible, but a more thorough accounting of the reliability of the science will be done if it is admitted.

In the 1993 Supreme Court of Canada case R. v. Marquard, the Supreme Court held that formal academic credentials are not required for someone to be considered an expert. ${ }^{55} \mathrm{In}$ fact, Canadian courts have explicitly stated that, at least for matters of resource development on Indigenous lands, experience is sufficient for expertise ${ }^{56}$ Formal credentials or education are not necessary to be an expert. However, for the question of admissibility of novel science, the person in question must be a scientist. In order to fit expert testimony into the $J-L J$ test, the testimony must be of a scientific nature. Finally, the British Columbia Superior Court has stated that interdisciplinary researchers can be useful. ${ }^{57}$ By analogy then, a group of experts some of which are experts in IPUs, and others who are experts in SUs, could in theory be considered experts for the purpose of co-production. ${ }^{58}$

\section{Admissibility of Oral History EVIdenCE}

In this section I will begin by examining the law on admissibility of oral evidence, followed by a review of the academic literature. The case law and the literature show that despite the fact that oral history evidence is ostensibly considered both reliable and necessary by the courts, it is not always treated as such. I will then examine the implications of this on the admissibility of co-production. It ought to be noted that I am not talking about the admissibility of oral history evidence only insofar as it pertains to establishing Aboriginal rights. Rather, I am framing this discussion in a broader context: co-produced information can be useful in many areas of the Canadian legal system. It is not only useful for the purpose

$J-L J$, supra note 50 at para 33 . This test for reliability has been upheld most recently by the Supreme Court in White Burgess Langille Inman v Abbott and Haliburton Co, 2015 SCC 23 at para 23.

Marquard, supra note 46 at 243.

Fairford First Nation v Canada (AG) (1998), 145 FTR 115 at para 5 (this case is distinguished from cases of co-production because it did not deal with novel science).

Reference re: Section 293 of the Criminal Code of Canada, 2011 BCSC 1588 at para 84.

While it might seem odd to have a group of people be experts in one topic, where perhaps none of those people fully understand the other group's work, this situation is actually quite common in science and is one of the major areas of study in social epistemology. See generally John Hardwig, "Epistemic Dependence" (1985) 82:7 J Philosophy 335; John Hardwig, "The Role of Trust in Knowledge" (1991) 88:12 J Philosophy 693 [Hardwig, "Role of Trust"]. 
of proving an Aboriginal right. Moreover, if we take John Borrows' argument about the multi-jurisdictional nature of the Canadian legal system seriously, we ought to have an account of how to deal with this sort of jointly produced evidence. ${ }^{59}$

We now turn to the law on admissibility criteria for oral history evidence. The historical leading authority on this topic is the 1996 Supreme Court of Canada case, $R$. v. Van der Peet.$^{60}$ Van der Peet is a case about Aboriginal rights, and sets out a test to "identify whether an applicant has established an aboriginal right protected by s. 35(1): in order to be an aboriginal right an activity must be an element of a practice, custom or tradition integral to the distinctive culture of the aboriginal group claiming that right., ${ }^{\prime \prime}$

In making its assessment of whether a particular Aboriginal right exists, "a court must take into account the perspective of the aboriginal people claiming the right." ${ }^{162}$ However the court must be cognizant of the fact that Aboriginal rights exist within the framework of the Canadian legal system. ${ }^{63}$ Van der Peet held that in determining whether an activity is an element of a custom that is integral to the culture of the Aboriginal group in question, the court must interpret the rules of evidence in a way that acknowledges the difficulties in proving claims from a time when there were no written records. ${ }^{64}$

The 1997 Supreme Court case, Delgamuukw v. British Columbia, clarified how the court should think about the admissibility of oral history evidence. ${ }^{65}$ The Supreme Court in Delgamuukw stated that while there are challenges with using oral history evidence, including the fact that such evidence is hearsay, ${ }^{66}$ "this type of evidence can be accommodated and placed on an equal footing with the types of historical evidence that courts are familiar with." ${ }^{97}$ The plaintiffs in Delgamuukw had adduced two types of oral history evidence known as adaawk and kungax. These are sacred repositories of the most important laws, history, and traditions of a House. ${ }^{68}$ Due to their importance, they are repeated at feasts, and dissenters can ensure the accuracy of the adaawk and kungax by objecting to details during the performance of the history. ${ }^{69}$ While the trial judge in Delgamuukw admitted these oral histories, he gave them no independent weight, and only used them to confirm other evidence. ${ }^{70} \mathrm{He}$ did so because he considered it impossible to

See generally John Borrows, Canada's Indigenous Constitution (Toronto, University of Toronto Press, 2010) at 107. As the majority of expert reports are authored by a single person, there is little case law on the admissibility of jointly-authored reports. Ghost written reports are inadmissible (Kushnir $v$ Macari, 2017 ONSC 307). But jointly authored reports are not ghost written. Reports with more than one author are generally not admissible where it is unclear which author is responsible for which part of the report (Heidebrecht $v$ Fraser-Burrard Hospital Society (1995), 15 BCLR (3d) 189 (SC); Jones $v M a, 2010$ BCSC 867). However, it seems possible to write a report that clearly delineates which author(s) are responsible for which sections of the report. This would address concerns with which author is to be cross-examined. This is an issue that could go to weight, rather than admissibility, especially given the importance of reconciliation. [1996] 2 SCR 507 [Van der Peet]. This test exists in the context of proving Aboriginal rights. We will discuss the applicability of the test outside that context in Part IV.

Ibid at para 46.

Ibid at para 49; $R$ v Sparrow, [1990] 1 SCR 1075 at 1112.

Van der Peet, ibid.

Ibid at para 68 .

[1997] 3 SCR 1010 [Delgamuukw].

Ibid at para 86.

Ibid at para 87 .

Ibid at para 93 .

Ibid.

Ibid at para 96. 
distinguish between the mythological aspects of the history, and the "real" aspects, because the verifying group was too small, and because they lacked specific detail about the land in question. ${ }^{71}$ At the Supreme Court, these reasons were overturned. Chief Justice Lamer writing for the majority stated that

if this reasoning were followed, the oral histories of aboriginal peoples would be consistently and systematically undervalued by the Canadian legal system, in contradiction of the express instruction to the contrary in Van der Peet that trial courts interpret the evidence of aboriginal peoples in light of the difficulties inherent in adjudicating aboriginal claims. ${ }^{72}$

Following Delgamuukw, courts have refined the reasons for admitting oral history evidence. In Mitchell v. M.N.R., the Supreme Court of Canada indicated that "[o]ral histories are admissible as evidence where they are both useful and reasonably reliable."73 The "usefulness" criterion may be met in two ways. First, by offering evidence that is not otherwise available, and second, by providing an Aboriginal perspective on the right being claimed. ${ }^{74}$ Again, note how this discussion takes place within the framework of determining the existence of rights. The "reliability" criterion is met if the witness represents a "reasonably reliable source of the particular people's history." 75 A special guarantee of reliability is not required, and inquiries into the ability of the witness to know the oral history evidence may be appropriate. ${ }^{76}$ Importantly, the Supreme Court in Mitchell explicitly states that a Eurocentric view of oral history is not an appropriate standard for judging such evidence:

[J]udges must resist facile assumptions based on Eurocentric traditions of gathering and passing on historical facts and traditions. Oral histories reflect the distinctive perspectives and cultures of the communities from which they originate and should not be discounted simply because they do not conform to the expectations of the non-aboriginal perspective. ${ }^{77}$

The framework set out in Delgamuukw and Van der Peet has received generally positive treatment by judges. In Tsilhqot'in Nation v. British Columbia, the British Columbia Supreme Court held that oral history evidence was reliable independent of any corroborating evidence, and that to hold otherwise would mean treating evidence in an ethnocentric manner. ${ }^{78}$ This case, and the reconsideration of the western approach to oral history evidence, demonstrates a significant change in jurisprudence regarding oral history. ${ }^{79}$ Since then, there have been a number of cases that have found oral history evidence to be both necessary and reliable. ${ }^{80}$

Ibid at para 97.

Ibid at para 98 .

2001 SCC 33 at para 31 [Mitchell].

Ibid at para 32 .

Ibid at para 33.

Ibid.

Ibid at para 34

Tsilhqot'in v British Columbia, 2007 BCSC 1700 at para 196, aff'd 2014 SCC 44.

Arthur J Ray, "Traditional Knowledge and Social Science on Trial: Battles Over Evidence in Indigenous Rights Litigation in Canada and Australia" (2015) 6:2 Intl Indigenous Policy J.

$80 \quad$ See e.g. $R$ v Goodon, 2008 MBPC 59; Klahoose First Nation v Sunshine Coast Forest District (District Manager), 2008 BCSC 1642; $R$ v Joseph, 2010 BCPC 401. 
However, many scholars have criticized the way courts treat oral history evidence in Canada since Delgamuukw, on the basis that certain ethnocentric assumptions can still be discerned. David Milward's excellent paper, "Doubting What the Elders Have to Say: A Critical Examination of Canadian Judicial Treatment of Aboriginal Oral History Evidence," points out that while the Supreme Court has been supportive of a broader approach to oral history evidence, the courts post-Delgamuukw have not always followed this approach. ${ }^{81}$ By arguing that oral history evidence should not be given "more weight than it can reasonably support," the courts undermine the value of oral evidence. ${ }^{82}$ This undermining process occurs through reinforcing western values as the standard by which evidence is measured. "Reasonably support" indicates some standard is needed to evaluate what sort of weight oral history evidence can support, and this standard is not typically considered to be an Aboriginal one. For instance, in Benoit v. Canada, the Federal Court of Appeal agreed with the Crown's expert witness Dr. von Gernet that “oral history evidence cannot be accepted, per se, as factual, unless it has undergone the critical scrutiny that courts and experts ... apply to the various types of evidence which they have to deal with." ${ }^{83}$ In this case, the oral evidence did not have the checks and balances that existed in Delgamuukw, and was passed between individuals in an informal manner. Because of this, the oral evidence was considered not sufficiently reliable, and was therefore inadmissible. ${ }^{84}$ Other scholars have reached similar conclusions about the judicial interpretation of Delgamuukw. Val Napoleon writes that the decision in Delgamuukw "filtered and altered the adaawk thereby creating a distorted legal truth about oral histories that now pervades the aboriginal rights discourse." $" 85$ The interpretation of the courts that the checks and balances create a piece of information that is static and unchanging through time undermines the flexibility of oral history, which can change to emphasize certain elements according to the context. ${ }^{86}$

Likewise, in Mathias v. Canada, the Federal Court found oral history evidence corroborated with documentary evidence to be more reliable. ${ }^{87}$ As such, the courts privilege western forms of evidence - that is, written evidence - over oral evidence even while apparently trying not to do so. ${ }^{88}$ This is essentially a claim about the reliability of oral evidence: oral history evidence is reliable if it meets the standards of documented history. ${ }^{89}$ This perhaps explains why some judges post-Delgamuukw still occasionally insist that oral history evidence be corroborated. ${ }^{90}$ In order to hold oral evidence to the documentary standard, it is easiest simply to determine whether it fits with evidence that almost by definition meets that standard.

(2010) 14:4 Intl J Evidence \& Proof 287 at 288.

Ibid; see also Mitchell, supra note 73 at para 39.

Benoit v Canada, 2003 FCA 236 at para 113 [Benoit].

Adam Daniel Etinson, "Aboriginal Oral History Evidence and Canadian Law” (2008) 6 Central European J Can Studies 97 at 101.

Val Napoleon, “Delgamuukw: A Legal Straightjacket for Oral Histories?” (2005) 20:2 CJLS 123 at 125. Ibid at 125, citing Margaret Anderson \& Marjorie Halpin, eds, Potlatch at Gitsegukla: William Beynon's 1945 Field Notebooks (Vancouver: University of British Columbia Press, 2000) at 35.

2000 CanLII 16282 at para 231 (FC).

Mariana Valverde, "The Crown in a Multicultural Age: The Changing Epistemology of (Post)colonial Sovereignty" (2012) 21:1 Soc \& Leg Stud 3 at 14-15.

Interestingly, an analogous problem arises in the context of scientific standards being used to evaluate IPUs. Some scientists do not see IPUs as sufficiently reliable to be used unless as a supplement or tool by SUs. See e.g. McGregor, supra note 2 at 146; Berkes, Berkes \& Fast, supra note 1 at 157.

See e.g. Benoit, supra note 83 at para 113. Recall that in Delgamuukw, supra note 65 at para 98 the Supreme Court explicitly states that corroboration is not required. 
Moreover, some courts have criticized oral history on the basis that it does not provide enough of a specific type of information, despite the fact that oral history was not needed to preserve that type of information. For instance, one judge ruled that oral histories did not do a sufficient job of describing the location where the activity in question took place, and rejected oral evidence on that ground. ${ }^{91}$ Milward argues that spelling out the geographical details was often not necessary for oral history, because that knowledge would be presumed in the listener. That is, listeners who live in an area and whose families had lived there for generations would not need to be told specific details about where the events of a story happened. $^{92}$

The reliability of oral histories as a method of preserving information has been acknowledged since well before Delgamuukw. Clay McLeod writes:

\begin{abstract}
The oral histories of Canada's First Nations are usually maintained by the elders in the community; in First Nations culture, elders are accorded the highest respect. Because of the respect accorded to the keepers of oral histories, the oral histories themselves are authoritative in First Nations culture. Moreover, the oral histories of First Nations have been passed from generation to generation, and they have been validated by each generation in the chain; the result is that oral histories are "enclothe[d]... with a cloak of trustworthiness." $" 93$
\end{abstract}

McLeod notes that several other historical cases have held oral history evidence to be reliable. In Re Paulette and Registrar of Titles (No. 2), the judge said that "[t]here is no doubt in my mind that [the oral] testimony was the truth and represented their best memory of what to them at the time must have been an important event." 94 Because of the reliability of oral history, McLeod predicted that the logic of the R. v. Khan decision could be applied to oral history. ${ }^{95}$

So we can see that while oral history evidence is admissible if it is both reliable and necessary, courts sometimes subscribe to ethnocentric conceptions of what "reliable" means by holding oral evidence to a documentary standard or by demanding it give more detail than it was meant to record. ${ }^{96}$ We now turn to the question of which framework - novel scientific evidence or oral history evidence - co-produced information fits into best. Sarazin, [2007] OJ No 5282 (QL) (Ont Ct J).

He likens this to The Adventures of Huckleberry Finn, in which Mark Twain never calls the river "The Mississippi River" because he assumes that the reader understands where the story takes place (ibid at 300-301, citing Mark Twain, The Adventures of Huckleberry Finn (Oxford: Oxford Paperbacks, 2008)). Clay McLeod, "The Oral Histories of Canada's Northern People, Anglo-Canadian Evidence Law, and Canada's Fiduciary Duty to First Nations: Breaking Down the Barriers of the Past" (1992) 30:4 Alta L Rev 1276 at 1279, citing $R$ v Dick (1988), [1989] 1 CNLR 132 at 134 (BC Prov Ct). Re Paulette and Registrar of Titles (No 2) (1973), 42 DLR (3d) 8 at 13 (NWTSC), aff'd (1976), [1977] 2 SCR 628.

$95 \quad$ McLeod, supra note 93 at 1287; Khan, supra note 31.

It is worth noting that several recent large-scale studies have generated similar data to oral history. See e.g. Maanasa Raghavan et al, "The Genetic Prehistory of the New World Arctic" (2014) 345:6200 Science 1020; John Lindo et al, "A Time Transect of Exomes From a Native American Population Before and After European Contact” (2016) 7:13175 Nature Communications 1; José A GuerreroAnalco et al, "Bioactive Phytochemicals From Canadian Boreal Forest Species Used Traditionally by Eastern James Bay Cree Aboriginals to Treat Diabetes Mellius" in Reinhard Jetter, ed, Phytochemicals — Biosynthesis, Function and Application, vol 44 (Cham: Springer, 2014) 57. 


\section{AdMissibility OF Co-ProduCED KNOWLEDGE}

So far we have seen that in the tests for admitting both novel scientific evidence and oral history evidence, the courts are deeply concerned with reliability. In this section of the article, I will examine how the definition of co-production given in Part I fits into these tests. We will see that co-produced information does not fit neatly into either framework.

\section{A. Co-Production And Novel Scientific Evidence}

At first glance, the most significant issue facing admitting co-produced evidence through the novel scientific evidence framework is that the rationale for modifying the rules of evidence arose within the framework of proving Aboriginal rights. When the courts modified the rules of evidence to allow oral history as an exception to hearsay, a large part of the justification was that the test for proving the existence of an Aboriginal right involved proving the existence of practices in the distant past. ${ }^{97}$ It is too onerous a burden to insist that Indigenous people prove this without recourse to their histories. Furthermore, it is ethnocentric to privilege non-Indigenous forms of history over Indigenous forms of history. ${ }^{98}$ It appears that this rationale likely would not exist outside the framework of proving Aboriginal rights.

This is because outside of the Aboriginal rights framework, the necessity criterion is significantly reduced. Note that there is a difference between necessity in the context of hearsay and in the context of expert evidence. With respect to hearsay, the necessity criterion is met if the evidence is not available elsewhere. ${ }^{99}$ For instance, if the declarant for whatever reason cannot come to court, the person who heard the declarant's statement may be allowed to testify. ${ }^{100}$ In the context of expert evidence, the necessity criterion is satisfied if that evidence is not commonly known. ${ }^{101}$ The latter of these would likely be met, as both science and Indigenous history are not commonly known. The former, however, may pose some difficulties.

When co-produced information is tendered as evidence outside of the context of proving an Aboriginal right, it is not being used to show the existence of a practice in the distant past. Rather, it is used to show some fact about the world in the present by making use of

Van der Peet, supra note 60 at para 46.

Delgamuukw, supra note 65 at para 98.

Hearsay is, to some extent, admissible in expert testimony ( $R v$ Lavallee, [1990] 1 SCR 852 [Lavallee]).

However, the weight given to expert testimony based on hearsay can be significantly constrained. Despite the fact (indeed, because of the fact) that co-produced evidence is in some way fundamentally based on hearsay, it is nevertheless a remarkably powerful source of information. Treating co-produced information in the same way as other hearsay evidence - that is, admitting it but not giving it weight - does not account for the unique qualities of co-produced information. Furthermore, such evidence is a different type of hearsay than the sort discussed in Lavallee and other cases of expert reports based on hearsay. Typically, expert reports containing hearsay involve the author of the report relying on the work of other experts or of some other person: see e.g. Mazur v Lucas, 2010 BCCA 473; R v Sheriffe, 2015 ONCA 880; Marchand (Litigation guardian of) v Public General Hospital Society of Chatham (2000), 51 OR (3d) 97 (CA). That is, the author of the report is entirely separate from the evidence on which they rely. However, in co-produced reports, the author is intimately involved in the production of the information, despite the fact that hearsay plays a role. As such, the current framework for dealing with hearsay in expert evidence does not adequately account for co-produced information. $B(K G)$, supra note 32 .

Mohan, supra note 33 at 23. 
information gleaned by generations of living with the land in a particular area. As such, the co-produced information is, at first glance, available elsewhere and fails the necessity criterion for hearsay. If a court is worried about the hearsay problem, it can simply turn to science that is done without Indigenous participation, thus side-stepping the issue of science informed by supposed hearsay.

However, this only holds if co-production is done poorly. Recall from the definition above that there are different ways co-production can be done, and that when co-production is done well it involves balanced input from both Indigenous peoples and scientists. ${ }^{102}$ That is, when co-production is done well, it is not just the addition of IPUs to SUs while keeping both discrete. Rather, co-production is a jointly informed circle where both IPUs and SUs modify each other to create a unique body of information. In this way, the framework of coproduction done well means that co-production is likely to meet the necessity criterion, as co-production is a unique method of gathering information about the world and similar evidence is not available elsewhere. This is not to say that purely scientific evidence cannot be adduced with regards to an issue about which co-produced information is adduced, but that co-produced information is generated in a unique fashion. As such, even outside the context of proving Aboriginal rights, it is possible for co-produced information to meet the necessity criterion.

Having dealt with the problem of necessity, we will now examine each of the criteria for admitting novel science, in order to determine whether co-produced information can be admitted under the $J-L J$ test.

\section{CRITERION 1:}

The first criterion is testability - a novel scientific method meets this criterion if it is capable of being falsified. ${ }^{103}$ Insofar as a co-production generates a hypothesis, it can be falsified. This is a question of the nature of the hypothesis. There are four jointly exhaustive options for how hypothesis production occurs in co-production projects:

(1) Indigenous peoples and scientists create different hypotheses;

(2) Indigenous peoples and scientists jointly create one hypothesis;

(3) Indigenous peoples create a hypothesis, but the scientists do not; and

(4) Scientists create a hypothesis, but Indigenous peoples do not. 
In Option 1, Indigenous peoples develop the hypothesis alongside scientists. Huntington et al., note of one co-production project that by

sharing observations and ideas triggered by ecological patterns and by their common experiences in the field, scientists and traditional knowledge holders collectively devised alternative hypotheses regarding bidarki [a type of mollusk] declines, ruling some out and narrowing in on others. ${ }^{104}$

In such cases, falsification can again occur, as the quote points out. When certain hypotheses are "ruled out," they are falsified. So from a real-world example, we can see that the testability criterion can be met where alternative hypotheses are created.

In Option 2, Indigenous peoples and scientists jointly create the hypothesis. In such cases, IPUs can be used as tools to inform research design rather than as the source of a hypothesis, and falsification is relatively straightforward. For example, if IPUs inform the methodology by noting that because caribou are part of the land, a study of caribou health should look not merely at the population of caribou, but also predator populations, lichen availability, and other related factors. Likewise, IPUs might inform the way the methodology of a study is implemented, for example by showing that looking at caribou health in a certain area is not representative of the population of caribou as a whole. In such cases, testability is met unproblematically because the hypothesis is capable of being disproved. ${ }^{105}$

In Option 3, Indigenous peoples create the hypothesis, but the scientists do not. In such cases, the spiritual aspect of IPUs may be concerning with respect to falsifiability. The spiritual aspect of IPUs may play a role in the hypothesis, but it is not necessary that it play such a role. ${ }^{106}$ For instance, if the hypothesis is that sea ice is shrinking, spirituality does not necessarily play a role that problematizes falsifiability. Furthermore, spiritual aspects can play an unproblematic role in informing the reason why a particular hypothesis is formed. Non-scientific values regularly play a direct role in determining reasons for doing science. ${ }^{107}$ So spiritual values informing reasons for inquiring into nature are not necessarily problematic. As such, the fact that there is a spiritual aspect to IPUs does not necessarily preclude IPUs from falsification. ${ }^{108}$

Finally, in Option 4, scientists create the hypothesis, but Indigenous peoples do not. In such cases, falsification is generally possible, given that science works through a process of

Huntington et al, supra note 13 at 440.

For example, the hypothesis "caribou are getting healthier" can be disproved by showing that caribou are not getting healthier.

Snively \& Corsiglia, supra note 1 at 23 write:

Essentially, criticisms of the validity and utility of indigenous science misapprehend the structure and mechanics of indigenous oral information systems. These systems do not simply assert that mythic-magical forces cause and control events. Large numbers of indigenous peoples observe, interpret, and orally report nature exhaustively. Rather than writing about their findings, they may use metaphoric stories to compress and organize important information so that it can be readily stored and accessed.

Heather E Douglas, Science, Policy, and the Value-Free Ideal (Pittsburgh: University of Pittsburgh Press, 2009) at 98-99.

Non-Indigenous scholars who participate in such research projects must be very careful about this. There is a long and troubling history of non-Indigenous peoples undermining the trust of Indigenous peoples when it comes to science, as I have alluded to above. The genetic research done on the Havasupai people is a paradigm case of scientists doing co-production in a deeply problematic fashion (see Sterling, supra note 15 ). 
falsification. As such, in each of the four ways that a hypothesis in the co-production context can be produced, it is at least in theory capable of being falsified. So co-produced information is capable of meeting the "testability" criterion.

\section{CRITERION 2:}

The second criterion assesses whether the method has been subject to peer review and publication. ${ }^{109}$ Much co-produced information has been published and has been subjected to peer review. ${ }^{110}$ However, this criterion may prove more difficult for some co-production projects that involve IPUs that, if published, would be harmful to the Indigenous people. ${ }^{111}$ Some knowledge held by Indigenous peoples might be used against them if published, and it is incumbent on researchers to be aware of this. As such, while IPUs have been published and peer reviewed, this is not always an unproblematic process. However, there are some steps that scientists and courts can take to mitigate this. For instance, keeping the raw data private while only publishing the results, or allowing information regarding secret women's ceremonies to be heard only by women. ${ }^{112}$

\section{CRITERION 3:}

The third criterion is the existence of methodological standards. ${ }^{113}$ This criterion is relatively unproblematic. There are standards for oral history ${ }^{114}$ and science, ${ }^{115}$ and there are accepted methodologies for performing co-production. ${ }^{116}$ As such, co-production meets the third criterion.

\section{CRITERION 4:}

The final criterion is whether the novel technique has been generally accepted in the scientific community. ${ }^{117}$ Within some scientific communities, co-production has been accepted. For instance, within the Canadian federal and provincial governments, there is a clear duty to consult. ${ }^{118}$ Environmental assessments "may take into account ... Aboriginal traditional knowledge." 119 So within a governmental setting, using IPUs alongside SUs is

$J-L J$, supra note 50 at para 33 .

See e.g. Noor Johnson et al, "The Contributions of Community-Based Monitoring and Traditional Knowledge to Arctic Observing Networks: Reflections on the State of the Field" (2015) 68:S1 ARCTIC 28; Tristan Pearce et al, "Inuit Traditional Ecological Knowledge (TEK), Subsistence Hunting and Adaptation to Climate Change in the Canadian Arctic" (2015) 68:2 ARCTIC 233.

Shackeroff \& Campbell, supra note 1 at 350.

Ray, supra note 79 .

$J$-LJ, supra note 50 at para 33 .

Napoleon, supra note 85. Note that these standards are not uniform across all Indigenous peoples, but that uniformity of standards across different cultures is not what is required.

Douglas, supra note 107; Robert K Merton, Social Theory and Social Structure (New York: The Free Press, 1968) at 607; Thomas S Kuhn, The Essential Tension: Selected Studies in Scientific Tradition and Change (Chicago: University of Chicago Press, 1977).

Huntington et al, supra note 13; Mymrin et al, supra note 25.

$J-L J$, supra note 50 at para 33 .

Haida Nation v British Columbia (Minister of Forests), 2004 SCC 73.

Canadian Environmental Assessment Act, 2012, SC 2012, c 19, s 19(3) [CEAA]. 
relatively unproblematic. However, combining IPUs and SUs in a co-production project is not necessarily accepted. The interim principles for the CEAA state that

environmental information (such as ATK [Aboriginal Traditional Knowledge] dealing with wildlife migration patterns), can be readily integrated with other environmental knowledge. Knowledge about, or based on, values and norms, is not as readily integrated with scientific data sets. Thus the main role [of Environmental Assessment] practitioners is to collect and organize any ATK that is provided, and bring to the attention of decision makers that ATK has been considered and how it has been considered. ${ }^{120}$

This is a problematic interpretation of both the role that values play in science and how IPUs function. ${ }^{121}$ It indicates that even in the government, co-production as a source of information is not necessarily accepted, insofar as it treats IPUs as somehow incompatible with science because IPUs are value-laden.

Outside of government-mandated settings, there is some scepticism about co-production among scientists. Co-production practitioners can fall into what are known as "unrecognized contributor" groups. Indigenous peoples

may be overlooked simply due to the lack of cognitive tools for identifying, articulating, or noticing them. Whyte and Crease (2010) label these "Unrecognized Contributor" cases, where groups or individuals with scientifically relevant knowledge are ignored or dismissed because they lack the formal education or credentials by which scientists, or contributory experts more generally, might have realized that they had specialist knowledge to contribute. ${ }^{122}$

Because IPUs are not recognized by institutions that confer expert status, it is difficult for some scientists to accept that IPUs are valid and reliable sources of information about the world.

Similarly, there are some scientists who do not support the use of IPUs at all. Two of the most vocal opponents to IPUs are Frances Widdowson and Albert Howard. They have argued that IPUs are so fundamentally different from SUs that SUs can never even validate IPUs. ${ }^{123}$ Likewise, Oscar Ortiz indicates that when IPUs do not fit with SUs, scientists ought to educate Indigenous people. ${ }^{124}$ The problem, of course, is that these authors view SUs as the standard to which all other forms of knowledge ought to be held. By doing so, they privilege non-Indigenous ways of knowing over Indigenous ways of knowing. Where such

Canadian Environmental Assessment Agency, "Considering Aboriginal Traditional Knowledge in Environmental Assessments Conducted Under the Canadian Environmental Assessment Act - Interim Principles" (2016), online: <www.ceaa.gc.ca/default.asp?lang=En\&n=4A795E76-1>.

Isaac, supra note 4 at 72 .

Kathryn S Plaisance \& Eric B Kennedy, "A Pluralistic Approach to Interactional Expertise” (2014) 47 Studies in History \& Philosophy Science 60 at 63, citing Kyle Powys Whyte \& Robert P Crease, "Trust, Expertise, and the Philosophy of Science" (2010) 177:3 Synthese 411 at 415. See also Brian Wynne, "May the Sheep Safely Graze? A Reflexive View of the Expert-Lay Knowledge Divide" in Scott Lash, Bronislaw Szerszynski \& Brian Wynne, eds, Risk, Environment and Modernity: Towards a New Ecology (London: SAGE Publications, 1996) 44.

123 Frances Widdowson \& Albert Howard, Disrobing the Aboriginal Industry: The Deception Behind Indigenous Cultural Preservation (Montreal: McGill-Queen's University Press, 2008).

124 Oscar Ortiz, "Understanding Interactions Between Indigenous Knowledge and Scientific Information" (1999) 7:3 Indigenous Knowledge \& Development Monitor 7. 
views can be found among scientists, it is not clear that co-production is "generally accepted." 125

The Supreme Court in $J-L J$ notes that the reliability assessment at this stage permits "identification of a relevant scientific community and an express determination of a particular degree of acceptance within that community." ${ }^{, 26}$ It is possible that by identifying a group of researchers who study the sorts of things also studied by Indigenous people that the "general acceptance" test could be met within that group. It seems plausible that, for instance, scientists who study ice thickness in the Arctic might be more accepting of coproduction than scientists whose work does not place them in contact with Indigenous peoples very often. Likewise, note that the language in this part of $J-L J$ is of scientific communities. This privileges SUs over IPUs in a colonial fashion. A full examination of this is beyond the scope of this article, but it seems likely that by expanding the scope of "general acceptance" to include Indigenous persons who are not professional scientists but who work with scientists, it is more likely that co-production would meet this fourth criterion.

As such, while co-production is capable of meeting the first three criteria set out in $J-L J$ with relatively few difficulties, the fourth criterion is problematic as co-production is not yet a generally accepted method of inquiry. We now turn to oral history evidence to determine whether co-produced information can be admitted under that framework.

\section{B. Co-Production ANd Oral History Evidence}

Recall that within the context of Aboriginal rights, "[o]ral histories are admissible as evidence where they are both useful and reasonably reliable." ${ }^{27}$ Usefulness is defined either as offering evidence that is not otherwise available, or providing an Aboriginal perspective on the right being claimed. ${ }^{128}$ Outside the context of demonstrating Aboriginal rights, the use of oral history evidence is less clear.

The main problem is that the use of oral history in co-production is not straightforward, and the resulting information generated by a co-production project is not oral history. That is, co-production is not oral history, but rather a way of using oral history to produce a new body of information. Although IPUs are typically developed while living with the land for generations, ${ }^{129}$ this does not mean that they incorporate specific claims about the world in a way that fits with the reliability indicia set out in Delgamuukw. Napoleon argues that Delgamuukw has placed an unwarranted focus on the memory retention methods used by the Gitksan, to the detriment of the oral history of other Indigenous peoples. ${ }^{130}$ Nor does the generational aspect of some IPUs mean that IPUs explicitly incorporate the historical

Note that this is the sort of question that is best answered empirically. Further research should include an empirical survey of scientists to determine to what extent co-production projects are accepted within various scientific communities.

$J-L J$, supra note 50 at para 33

Mitchell, supra note 73 at para 31 .

Ibid at para 32.

See Berkes, Berkes \& Fast, supra note 1 at 146 who write that IPUs are "a cumulative body of knowledge and beliefs, evolving by adaptive processes and handed down through generations by cultural transmission."

Napoleon, supra note 85 at 136. 
information into co-production projects in a way such that it is evident in the final product of such a project. The information generated by a co-production project (and for which the authors of the information would be called to testify about) might not be explicitly related to the oral history that informed it. For example, oral history about bears could inform a coproduction project resulting in information about the health of Saskatoon berries. ${ }^{131}$ Recall that the definition of IPUs is not co-extensive with oral history because IPUs involve the lived experience of an Indigenous person with the land. So while oral history informs IPUs, which then inform co-production, other aspects of Indigenous knowledge besides oral history also inform the co-production process. As such, it is possible that oral history might play only a small role in a co-production project, making it unlikely that such a project would be admitted under the oral history framework. Similarly, IPUs might also be informed by an Indigenous person's observations of the land over a single lifetime, rather than intergenerationally (what Service et al. call "local ecological knowledge"). ${ }^{132}$ Such information would likely not fit into the hearsay exception for oral history, as it would fail the necessity criterion.

So we can see that the interconnection of IPUs; more recent personal, non-historical observations; and scientific observations is complex. As such, although oral history might inform co-production, it does so to varying degrees, and the resulting information might not be oral history. It is unclear, but somewhat unlikely that courts would admit co-produced information, which is not oral history, under the oral history exception.

\section{NeXt StePS}

As we have seen, co-produced information does not fit well into either the novel science or oral history admissibility frameworks. It is beyond the scope of this article to offer a fullydeveloped solution to this complex problem, and such a solution will likely take a great deal of scholarly work to develop. That being said, I will sketch out a possible path forward. I have already noted that the "general acceptance" criterion allows for the identification of a relevant sub-group who accept the novel scientific technique, which is one plausible solution. Another promising solution is through the education of scientists on co-production, and through promoting collaboration between Indigenous peoples and scientists. The more scientists understand about what IPUs are, and how IPUs are commensurable with SUs, it is likely that more scientists will want to work alongside Indigenous peoples. Trust is infused throughout science ${ }^{133}$ and co-production. ${ }^{134}$ By fostering trust, co-production projects can

131 Jeanette Armstrong, “Natural Ways of Knowing: Positioning Indigenous Peoples' Knowledge in Natural Resource Management" in Henry Michel \& Donald V Gayton, eds, Linking Indigenous Peoples' Knowledge and Western Science in Natural Resource Management: Conference Proceedings (Kamloops: Southern Interior Forest Extension and Research Partnership, 2002) 11. Armstrong says that $[\mathrm{w}]$ hat we mean by [a story about talking with bears] is that many generations ago the animal showed us its knowledge and the important things we need to know. We mean we understood and communicated and listened to what bear is saying to us every day out there, and what it's still saying to us every day out there. Bear said "I'm your gardener for those berries you love. I go around and fertilize them, I plant them". The bear fixes it up with sweet chemicals that allow it to grow in ground which is very difficult to grow anything. Bear gave us a gift to help and sustain us because he also likes those berries. Our bear is never chased away in our communities and killed because they come to visit us in our homes (ibid at 13).

Service et al, supra note 1 .

Hardwig, "Role of Trust," supra note 58.

Isaac, supra note 4 at $45,57$. 
improve the knowledge Indigenous and non-Indigenous peoples have about our world, while building relationships between both peoples.

\section{CONCLUSION}

Co-production is an emerging source of information about the world, but it is one that has not been adequately theorized in the legal literature. Because co-production contains aspects of both novel science and oral history, it is not clear how it can be admitted into evidence. I have argued that co-produced information does not clearly fit into either admissibility framework. With respect to the novel science framework, co-produced information fits into the criteria of testability, peer review, and standards with only a few problems, but would likely fail the general acceptance test. However, if scientists are educated about coproduction, or if it is possible to delineate a group of scientists who are more likely to accept co-production as the "relevant group," then it may be possible for co-production to be admitted as evidence through the novel science framework. Turning to the oral history framework, co-produced information is less likely to be admitted, because oral history is only a part, and not a necessary part, of co-produced information. As such, courts will likely be reluctant to bend the rules of evidence to admit it. Further research is needed to determine whether co-produced information can be admitted under the novel science framework. 